\title{
Collar Dosing Unit
}

National Cancer Institute

\section{Source}

National Cancer Institute. Collar Dosing Unit. NCI Thesaurus. Code C82481.

A unit of presentation used to represent the quantity of product that is found in a single discrete entity where the pharmaceutical dose form is a type of collar. 